\title{
Circulación del virus sincicial respiratorio en Buenos Aires. Su relación con el cambio climático global
}

\author{
Seasonality of respiratory syncytial virus in Buenos Aires. \\ Relationship with global climate change
}

\author{
Dr. Fernando Ferrero ${ }^{a}$, Dr. Fernando Torres ${ }^{a}$, Lic. Rosana Abrutzkyb , Dra. María F. Ossorio ${ }^{a}$, \\ Dra. Alejandra Marcos', Dra. Claudia Ferrario y Dra. María J. Riale
}

\section{RESUMEN}

Introducción. El cambio climático global podría modificar la circulación del virus sincicial respiratorio (VSR). Evaluamos si la temporada de VSR se modificó en los últimos 20 años y su correlación con la temperatura media anual.

Métodos. Estudio transversal, en el que se utilizaron registros de VSR y temperatura de la Ciudad de Buenos Aires (19952014). Para cada año, describimos el inicio, el fin y la duración de la temporada de VSR y su correlación con la temperatura media anual.

Resultados. Se identificaron 8109 infecciones por VSR. La duración de la temporada disminuyó significativamente (1995: 29 semanas vs. 2014: 17 semanas; R: 0,6; p <0,001), debido a una finalización más precoz (1995: semana 45 vs. 2014: semana 33; R: $0,6 ; \mathrm{p}<0,001)$. No se observó correlación entre la temperatura media anual y la duración, el comienzo ni la finalización de la temporada de VSR.

Conclusión. En los últimos 20 años, la duración de la temporada de VSR se acortó significativamente, sin correlación con la temperatura.

Palabras clave: virus sincicial respiratorio humano, infecciones del tracto respiratorio, cambio climático, calentamiento global.

http:/ /dx.doi.org/10.5546/aap.2016.52

a. Docencia e Investigación, Hospital General de Niños Pedro de Elizalde.

b. Instituto de Investigaciones Gino Germani, Facultad de Ciencias Sociales, Universidad de Buenos Aires.

c. Ministerio de Salud, Gobierno de la Ciudad de Buenos Aires.

d. División Promoción y Protección de Salud.

e. Laboratorio Central.

Hospital General de Niños Pedro de Elizalde.

Correspondencia:

Dr. Fernando Ferrero: fferrero@intramed.net

Financiamiento: Ninguno.

Conflicto de intereses: Ninguno que declarar.

Recibido: 9-7-2015

Aceptado: 19-8-2015

\section{INTRODUCCIÓN}

Las infecciones respiratorias agudas son una importante causa de morbimortalidad, y el virus sincicial respiratorio (VSR) es su agente más frecuente en menores de 2 años. ${ }^{1}$ Aunque, a nivel global, la carga de enfermedad atribuible al VSR es desconocida, se estima que, en 2005, a nivel mundial, entre 66000 y 199000 niños murieron por infección respiratoria aguda asociada a este virus. ${ }^{1}$

La temporada de circulación del VSR varía según las regiones y los climas, y su inicio y duración podrían modificarse por condiciones ambientales. ${ }^{2}$ En climas templados, el VSR circula durante otoño e invierno, ligado a disminución de la temperatura y aumento de la humedad. ${ }^{3}$

En los últimos años, como consecuencia del efecto invernadero, se ha producido un calentamiento global, con aumento de las temperaturas promedio. A comienzos del siglo XXI, la temperatura media mundial fue $0,6{ }^{\circ} \mathrm{C}$ mayor que la del siglo XX. ${ }^{4}$ Adicionalmente, en las grandes áreas urbanas, el fenómeno conocido como "isla de calor" contribuye al aumento en las temperaturas locales, hecho bien documentado en la Ciudad de Buenos Aires. ${ }^{5}$

Estos cambios en el clima local podrían condicionar variaciones en los patrones de circulación del VSR. Así, Donaldson encontró, en Inglaterra, un acortamiento del período de infecciones por VSR en relación con el aumento de la temperatura. ${ }^{6}$

El conocimiento sobre cambios en la circulación del VSR es fundamental para diseñar acciones sanitarias específicas, lo que puede -inclusotener impacto en el empleo de algunas medidas preventivas, como la administración del palivizumab.

No existen, al momento, publicaciones en nuestro medio que evalúen la posible asociación entre el cambio climático y las modificaciones en la circulación del VSR. Nuestro objetivo fue evaluar si la duración de la temporada de 
VSR se modificó en los últimos 20 años y si existe correlación entre la modificación de la temperatura media anual y la duración de la temporada de VSR.

\section{MATERIAL Y MÉTODOS}

Estudio transversal, en el que se utilizaron registros de identificación de VSR de un hospital pediátrico de la Ciudad de Buenos Aires de los años 1995-2014, ordenados por semana epidemiológica (datos de la División Laboratorio del hospital). Los registros de temperatura media anual (en grados Celsius) de los años 1995-2014 de la Ciudad de Buenos Aires fueron provistos por el Servicio Meteorológico Nacional.

Variables de resultado:

- Comienzo de la temporada de VSR: Para cada año, primera semana epidemiológica en que el número de identificaciones de VSR sea mayor que el $60 \%$ del promedio de identificaciones semanales del año. ${ }^{6}$

- Fin de la temporada de VSR: Para cada año, primera semana epidemiológica en que el número de identificaciones de VSR sea menor que el $60 \%$ del promedio de casos semanales del año. ${ }^{6}$

- Duración de la temporada de VSR: Para cada año, número de semanas epidemiológicas comprendidas entre el inicio y el fin de la temporada.
Consideraciones estadísticas: Para cada año, se describe el inicio, el fin y la duración de la temporada de VSR y la temperatura media anual; las variaciones de cada uno fueron evaluadas por regresión lineal simple. Además, se compararon los promedios de semanas de duración, inicio y fin entre ambas mitades del período de estudio (19952004 vs. 2005-2014) con la prueba t de Student. La correlación entre la temperatura media anual y el inicio y el fin de la temporada de VSR (número de semana epidemiológica) y entre la temperatura media anual y la duración de la temporada de VSR (en semanas epidemiológicas) se evaluó mediante la correlación de Pearson (coeficiente P).

Consideraciones éticas: Los datos de temperatura son de dominio público. Los referidos a VSR se encuentran absolutamente disociados de cualquier dato filiatorio.

Se solicitó y obtuvo autorización institucional (Comité de Docencia e Investigación y Comité de Ética en Investigación). El estudio se inscribió en el Registro Público de Investigaciones del Gobierno de la Ciudad de Buenos Aires (467/14).

\section{RESULTADOS}

En el período estudiado, se registraron 8109 identificaciones de VSR. Se analizaron las temperaturas medias anuales y el comienzo, la finalización y la duración de la temporada de VSR (Tabla 1).

Tabla 1. Temporada de circulación de virus sincicial respiratorio y temperatura anual promedio en la Ciudad de Buenos Aires

\begin{tabular}{|c|c|c|c|c|}
\hline \multirow[t]{2}{*}{ Año } & \multicolumn{3}{|c|}{ Temporada de circulación de virus sincicial respiratorio } & \multirow[t]{2}{*}{ Temperatura media anual } \\
\hline & Semana de inicio & Semana de finalización & Duración & \\
\hline 1995 & 17 & 45 & 29 & 17,8 \\
\hline 1996 & 20 & 47 & 28 & 18,3 \\
\hline 1997 & 13 & 39 & 27 & 18,5 \\
\hline 1998 & 17 & 46 & 30 & 17,8 \\
\hline 1999 & 11 & 40 & 35 & 17,7 \\
\hline 2000 & 12 & 39 & 29 & 17,7 \\
\hline 2001 & 16 & 47 & 24 & 18,4 \\
\hline 2002 & 16 & 40 & 32 & 18,0 \\
\hline 2003 & 18 & 46 & 24 & 17,7 \\
\hline 2004 & 17 & 36 & 30 & 18,1 \\
\hline 2005 & 18 & 38 & 21 & 17,9 \\
\hline 2006 & 17 & 39 & 19 & 18,2 \\
\hline 2007 & 17 & 33 & 17 & 17,4 \\
\hline 2008 & 18 & 36 & 19 & 18,5 \\
\hline 2009 & 17 & 39 & 23 & 18,2 \\
\hline 2010 & 14 & 28 & 15 & 18,2 \\
\hline 2011 & 14 & 30 & 17 & 17,9 \\
\hline 2012 & 17 & 32 & 16 & 18,3 \\
\hline 2013 & 18 & 36 & 19 & 18,1 \\
\hline 2014 & 17 & 33 & 17 & 18,3 \\
\hline
\end{tabular}


El inicio de la temporada de VSR fue en la semana 17 tanto en 1995 como en 2014 (la semana de inicio más precoz fue la 11 y la más tardía, la 20; mediana $=17$; $\mathrm{R}$ : 0,02; $\mathrm{p}=0,4$ ).

La finalización de la temporada de VSR fue en la semana 45 en 1995 y en la 33 en 2014 (la semana de finalización más precoz fue la 28 y la más tardía, la 47; mediana $=39$; R: 0,6; $\mathrm{p}<0,001$ ).

La duración de la temporada de VSR fue de 29 semanas en 1995 y 17 en 2014 (la menor duración fue de 15 semanas y la mayor, de 35; mediana $=24 ; \mathrm{R}: 0,6 ; \mathrm{p}<0,001$ ) (Figura 1).

Al comparar la primera mitad del período (1995-2004) con la segunda (2005-2014), observamos menor duración $(28,8$ vs. 18,3 semanas; $\mathrm{p}<0,001)$ y finalización más precoz (semana 42,5 vs. semana 34,4; $\mathrm{p}<0,001$ ), sin diferencias en el inicio de la temporada (semana 15,56 vs. semana 16,$7 ; p=0,2$ ).

La temperatura media anual fue $17,8^{\circ} \mathrm{C}$ en 1995 y $18,3^{\circ} \mathrm{C}$ en 2014 , con un aumento promedio de $0,02{ }^{\circ} \mathrm{C}$ por año (R: 0,04; $\mathrm{p}=0,2$ ) (Figura 1 ).

No se observó correlación entre la temperatura media anual y la duración (P: 0,$24 ; \mathrm{p}=0,2)$, el inicio (P: 0,$2 ; p=0,4)$ ni la finalización (P: 0,28 ; $\mathrm{p}=0,7)$ de la temporada de VSR.

\section{DISCUSIÓN}

En la mayor parte del mundo, -se ha verificado un aumento de la temperatura media anual, y en algunas regiones-, dicho incremento superó los $2{ }^{\circ} \mathrm{C}$. En Argentina, el incremento de temperaturas durante el siglo XX fue ligeramente menor que el promedio global; sin embargo, durante las últimas décadas, se verificó una tendencia a temperaturas extremas y olas de calor. ${ }^{8}$
El impacto del ambiente sobre la salud está muy documentado, en particular el del clima y el de la contaminación atmosférica. En relación al clima, existiría un efecto más pronunciado sobre enfermedades respiratorias. ${ }^{9}$ Se estima que este impacto del cambio climático en la salud será muy importante a corto plazo. ${ }^{10}$

La infección por virus sincicial respiratorio es una de las más comunes en la infancia y tiene considerable impacto sanitario, económico y social en el mundo entero. ${ }^{11}$

A pesar de que, -en escenarios con adecuado acceso a la salud-, la enfermedad por VSR puede ser convenientemente manejada, la magnitud de esta patología implica un enorme consumo de recursos, lo que hace imprescindible una correcta planificación de las estrategias para enfrentarla. ${ }^{12}$ Una mejor comprensión de los factores determinantes de la circulación del virus podrá contribuir a mejorar la eficiencia en el uso de recursos.

En especial frente a medidas particularmente onerosas, como el empleo de palivizumab, ${ }^{13}$ la costo-efectividad es decisiva a la hora de decidir su utilización. Recientemente, se ha calculado cómo puede variar esta ecuación sobre la base de diferentes estimaciones en la tasa de mortalidad por bronquiolitis. ${ }^{14}$ De similar forma, es muy probable que una temporada de VSR consistentemente más corta justifique modificar el número de dosis del anticuerpo monoclonal, lo que puede mejorar de modo sustancial la costoefectividad de la medida.

Nuestro estudio posee como limitación que se restringe a una sola institución. Sin embargo, los datos utilizados provienen de un hospital

Figura 1. Temperatura media anual y duración de la temporada de virus sinicicial respiratorio, Ciudad de Buenos Aires, 1995-2014

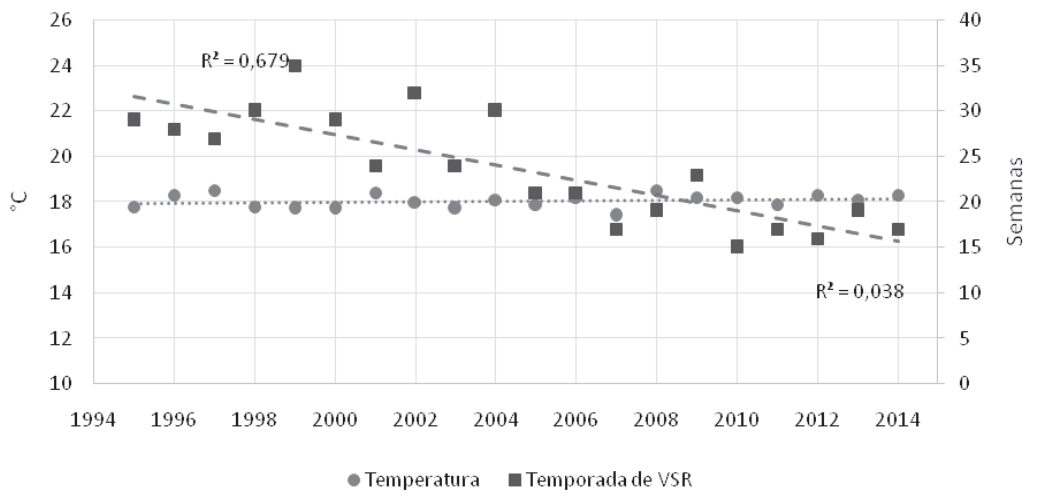


que forma parte del Sistema de Vigilancia Epidemiológica Nacional, desde su creación, sus técnicas se encuentran absolutamente estandarizadas y la mayoría de los pacientes provienen de la comunidad que representan.

En el período estudiado, pudimos verificar un acortamiento paulatino en la duración de la temporada de VSR, a expensas de una finalización cada vez más precoz. Esto es consistente con lo reportado por los Centros para el Control y la Prevención de Enfermedades (Centers for Disease Control and Prevention; CDC, por sus siglas en inglés) para EE. UU. en los últimos años (temporadas de VSR de 17 semanas, en promedio). ${ }^{15}$ Sin embargo, la serie de tiempo elegida (20 años) fue corta para evidenciar diferencias significativas en la temperatura media. Este hecho puede ser responsable de no haber podido demostrar una correlación directa entre el aumento de la temperatura y el acortamiento de la temporada de VSR. Teniendo en cuenta que, al considerar períodos ligeramente más largos, es posible verificar modificaciones significativas en la temperatura media anual, ${ }^{8}$ es razonable pensar que, si se contara con datos de VSR de un período más largo, se podría arribar a resultados similares a los de Donaldson. ${ }^{6}$

\section{CONCLUSIÓN}

En los últimos 20 años, la duración de la temporada de VSR en Buenos Aires se acortó significativamente. No se encontró correlación entre la temperatura media anual y la duración de la temporada ni su fecha de inicio, o fin.

\section{Agradecimiento}

A la Lic. Irene Barnatán, jefa del Banco Nacional y Regional de Datos Meteorológicos y Ambientales, Servicio Meteorológico Nacional (Argentina), por el acceso a los datos utilizados.

\section{REFERENCIAS}

1. Nair H, Nokes DJ, Gessner BD, Dherani M, et al. Global burden of acute lower respiratory infections due to respiratory syncytial virus in young children: a systematic review and meta-analysis. Lancet 2010;375(9725):1545-55.

2. Sloan C, Moore ML, Hartert T. Impact of pollution, climate, and sociodemographic factors on spatiotemporal dynamics of seasonal respiratory viruses. ClinTransl Sci 2011;4(1):48-54.

3. Meerhoff TJ, Paget JW, Kimpen JL, Schellevis F. Variation of respiratory syncytial virus and the relation with meteorological factors in different winter seasons. Pediatr Infec Dis J 2009;28(10):860-6.

4. Mahishale V. Climate change and respiratory health: Time to act!! J Sci Soc 2014;41(3):149-50.

5. De Garín A, Bejarán R. Mortality rate and relative strain index in Buenos Aires city. Int J Biometeorol 2003;48(1):31-6.

6. Donaldson GC. Climate change and the end of the respiratory syncytial virus season. Clin Infect Dis 2006;42(5):677-9.

7. Murray J, Saxena S, Sharland M. Preventing severe respiratory syncytial virus disease: passive, active immunization and new antivirals. Arch Dis Child 2014;99(5):469-73.

8. Barros VR, Boninsegna JA, Camilloni IA, Chidiak M, et al. Climate change in Argentina: trends, projections, impacts and adaptation. Wiley Interdiscip Rev Clim Change 2015;6(2):151-69.

9. Paynter S, Ware RS, Weinstein P, Williams G, et al. Childhood pneumonia: a neglected, climate-sensitive disease? Lancet 2010;376(9755):1804-5.

10. Patz JA, Frumkin H, Holloway T, Vimont DJ, et al. Climate change: challenges and opportunities for global health. JAMA 2014;312(15):1565-80.

11. Díez-Domingo J, Pérez-Yarza EG, Melero JA, SánchezLuna M, et al. Social, economic, and health impact of the respiratory syncytial virus: a systematic search. BMC Infect Dis 2014;14:544.

12. Byington CL, Wilkes J, Korgenski K, Sheng X. Respiratory syncytial virus-associated mortality in hospitalized infants and young children. Pediatrics 2015;135(1):e24-31.

13. American Academy of Pediatrics Committee on Infectious Diseases, American Academy of Pediatrics Bronchiolitis Guidelines Committee. Updated guidance for palivizumab prophylaxis among infants and young children at increased risk of hospitalization for respiratory syncytial virus infection. Pediatrics 2014;134(2):415-20.

14. Andabaka T, Nickerson JW, Rojas-Reyes MX, Rueda JD, et al. Monoclonal antibody for reducing the risk of respiratory syncytial virus infection in children. Cochrane Database Syst Rev 2013;4:CD006602.

15. Centers for Disease Control and Prevention. Respiratory syncytial virus activity: United States, July 2007-December 2008. MMWR Morb Mortal Wkly Rep 2008;57(50):1355-8. 